\title{
Review Article \\ Relationship between Periodontitis and Rheumatoid Arthritis: Review of the Literature
}

\author{
Vilana Maria Adriano Araújo, ${ }^{1}$ Iracema Matos Melo, ${ }^{2}$ and Vilma Lima ${ }^{1}$ \\ ${ }^{1}$ Departamento de Fisiologia e Farmacologia, Universidade Federal do Ceará (UFC), Rua Coronel Nunes de Melo, \\ 1127 Rodolfo Teófilo, 60430-270 Fortaleza, CE, Brazil \\ ${ }^{2}$ Faculdade de Farmácia, Odontologia e Enfermagem, Universidade Federal do Ceará (UFC), Rua Alexandre Baraúna, \\ 949 Rodolfo Teófilo, 60430-160 Fortaleza, CE, Brazil
}

Correspondence should be addressed to Vilma Lima; villima@yahoo.com.br

Received 27 March 2015; Revised 8 June 2015; Accepted 24 June 2015

Academic Editor: Claudio A. Mastronardi

Copyright (c) 2015 Vilana Maria Adriano Araújo et al. This is an open access article distributed under the Creative Commons Attribution License, which permits unrestricted use, distribution, and reproduction in any medium, provided the original work is properly cited.

\begin{abstract}
Periodontitis (PD) and rheumatoid arthritis (RA) are immunoinflammatory diseases where leukocyte infiltration and inflammatory mediators induce alveolar bone loss, synovitis, and joint destruction, respectively. Thus, we reviewed the relationship between both diseases considering epidemiological aspects, mechanical periodontal treatment, inflammatory mediators, oral microbiota, and antibodies, using the keywords "periodontitis" and "rheumatoid arthritis" in PubMed database between January 2012 and March 2015, resulting in 162 articles. After critical reading based on titles and abstracts and following the inclusion and exclusion criteria, 26 articles were included. In the articles, women over 40 years old, smokers and nonsmokers, mainly constituted the analyzed groups. Eight studies broached the epidemiological relationship with PD and RA. Four trials demonstrated that the periodontal treatment influenced the severity of RA and periodontal clinical parameters. Nine studies were related with bacteria influence in the pathogenesis of RA and the presence of citrullinated proteins, autoantibodies, or rheumatoid factor in patients with PD and RA. Five studies investigated the presence of mediators of inflammation in PD and RA. In summary, the majority of the articles have confirmed that there is a correlation between PD and RA, since both disorders have characteristics in common and result from an imbalance in the immunoinflammatory response.
\end{abstract}

\section{Introduction}

Periodontitis (PD) is a chronic inflammatory disease where resident cells and preformed mediators induce leukocyte infiltration and progressive destruction of the tooth supporting tissues as a result of interaction between bacterial products, cell populations, and mediators in disease-susceptible individuals $[1,2]$. This is also influenced by genetic and environmental risk factors and is characterized as a complex disease with multifactorial etiology $[3,4]$. In this context, environmental factors, including oral hygiene/bacterial plaque, smoking, and stress, play an important role in the expression of PD [3]. Furthermore, it has been evidenced by some authors that there is a joint influence of polymorphisms in multiple genes [5], such as the genes of IL-10 [6] and IL-6 [7].

Polymorphonuclear neutrophils (PMNs) represent the first line of defense to protect the host from periodontal pathogens in the gingival sulcus and junctional epithelium. Data on the role of the pathogenesis of periodontitis are mixed. PMNs are a critical arm of defense against periodontitis, but bacterial evasion of the neutrophil microbicidal machinery coupled with delayed neutrophil apoptosis may transform the neutrophil from defender to perpetrator [8]. Actually, these cells can release a variety of factors, such as reactive oxygen species, collagenases, and other proteases, $[1,9]$, such as stimulation from a wide range of cytokines. In this scenario, macrophages can act as antigen-presenting cells, promoting the activation of lymphocytes [1]. Therefore, the cellular concentration of neutrophils in the inflammatory infiltrates decreases during the transition between gingivitis and periodontitis, in which there is a predominance of lymphocytes [9].

It has been described that proinflammatory cytokines, prostaglandin $\mathrm{E}_{2}$, matrix metalloproteinase (MMP), nitric 


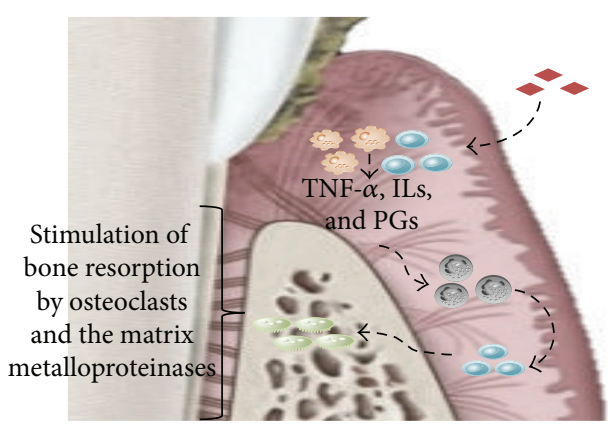

(a)

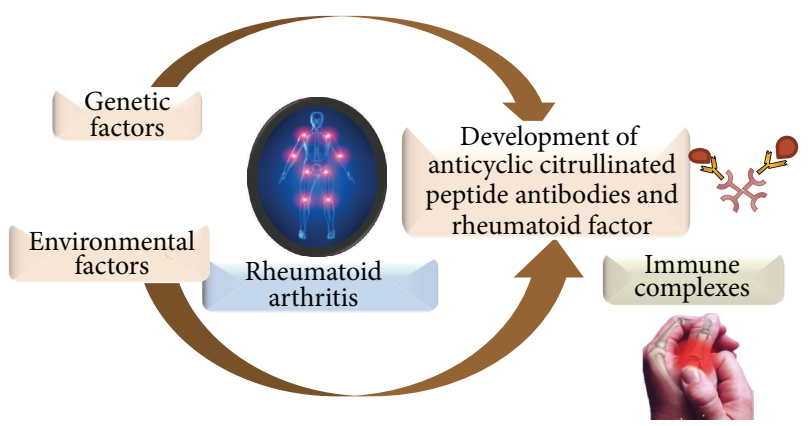

(b)

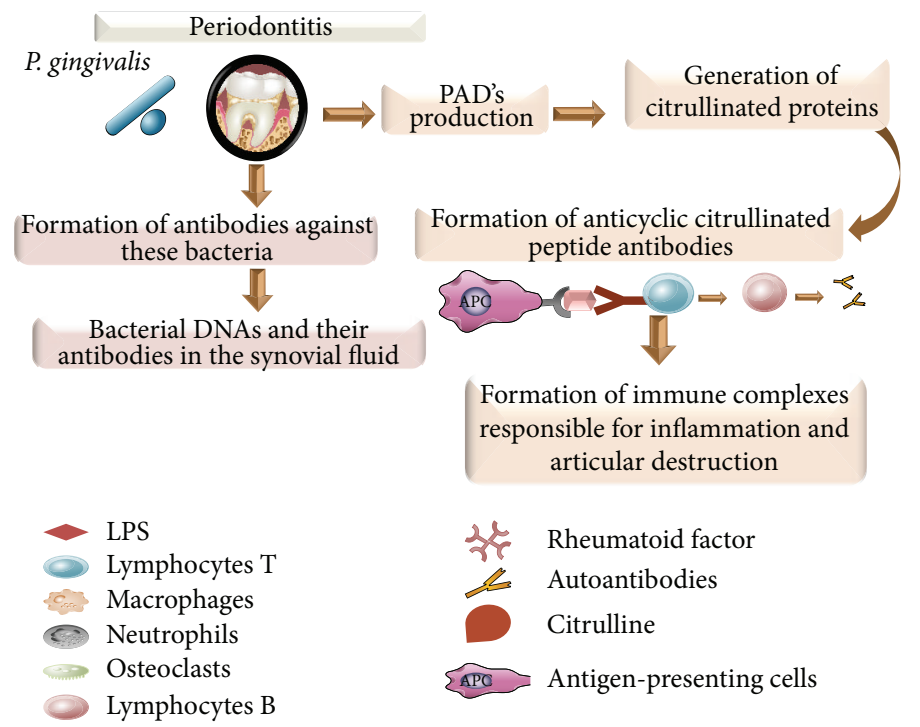

(c)

Figure 1: Scheme on the relationship between periodontitis and rheumatoid arthritis. (a) Pathogenesis of periodontitis and the effects promoted by lipopolysaccharides present in periodontopathogens. (b) The involvement of genetic and environmental factors in the development of rheumatoid arthritis. (c) Possible mechanisms that explain the relationship between rheumatoid arthritis and periodontitis.

oxide (NO), and other inflammatory mediators play a crucial role in the pathogenesis of PD [10-12]. Moreover, an increase of TNF- $\alpha$, IL-1 $\beta$, IL-6, IL-11, and IL-17 can induce osteoclastogenesis by increasing the expression of Receptor Activator of NF- $\kappa \mathrm{B}$ Ligand (RANKL) and by reducing the osteoprotegerin (OPG) production in osteoblasts and stromal cells [13]. In fact, it was demonstrated that IL-17 and RANKL were overregulated and IL-10, an anti-inflammatory cytokine, and TGF- $\beta 1$ were downregulated in active periodontal lesions compared with inactive lesions [14, 15] (Figure 1(a)).

Considering that an imbalance between bone formation and resorption is also linked to various diseases, studies suggest that PD may be a risk factor for other diseases [16], such as rheumatoid arthritis (RA) [17], but without consensus. Although pathogenesis of RA is not completely understood, it is recognized that the activation of the complement system is important in disease development [18], the abnormal response of circulating lymphocytes from patients, and an alteration in the structure of these cells, which contribute to the autoimmunity, immunosuppression, and the genesis of the disease [19]. Studies report there is a correlation between both PD and RA since the mechanisms for the development of RA have consonance with the pathogenesis of chronic PD. In fact, RA is defined as an inflammatory and autoimmune disease characterized by accumulation of leukocyte inflammatory infiltrate in the synovial membrane, as well as mediators such as PGE 2 , TNF- $\alpha$, IL- $1 \beta$, IL-6, IL-12, IL-17, IL18, IL-33, granulocyte macrophage colony-stimulating factor (GM-CSF), Monocyte Colony-Stimulating Factor (M-CSF), RANKL, MMPs, and NO, all being found in the synovial fluid [20-24], and leading to synovitis and joint architecture destruction.

Some studies have suggested that the susceptibility of RA may be associated with genetic or environmental factors [25]. One of the most important genetic factors is the human leukocyte antigen (HLA) class II. Certain alleles of this antigen are often associated with the development of rheumatoid arthritis (HLA-DRB1*0101, HLA-DRB1 ${ }^{*} 0102$, HLADRB1*0401, HLA-DRB1*0404, HLA-DRB1*0405, HLADRB1 ${ }^{*} 0408$, HLA-DRB1 ${ }^{*} 0410$, HLA-DRB1* 1001 , and HLADRB1*1402) [14]. Other factors include the allele of $620 \mathrm{~W}$ of PTPN22 (protein tyrosine phosphatase nonreceptor type 
22), a gene encoding tyrosine phosphatase that is involved in controlling the intracellular signaling triggered through $\mathrm{T}$ and $B$ receptors [26]; C5-TRAF1, which can interfere with disease susceptibility and severity of the alteration in the structure, function, and levels of complement component c5/factor 1 associated with the TNF receptor [27]; gene encoding the CTLA4 (cytotoxic T lymphocyte antigen-4), the protein responsible for the regulation of $\mathrm{T}$ lymphocyte activation [28]; peptidylarginine deiminase (PAD2), the enzyme responsible for the generation of citrullinated proteins, which are related to the formation of anticyclic citrullinated peptide autoantibodies [29] (Figure 1(b)). With regard to environmental factors, smoking is a risk factor that duplicates the risk of developing RA, but its effect is limited to those with antibodies to citrullinated peptides $[30,31]$. Other factors refer to the excessive consumption of coffee (more than 10 cups daily) which can be related to the development of the disease [32] and bacterial microbiota, including oral bacterial species which can participate in the etiopathogenesis of RA [33]. On the other hand, the intake of alcohol may exert a protective effect in rheumatoid arthritis in a dose-dependent manner [32]. The literature shows that the basic difference between both diseases is that RA is an inflammatory autoimmune disease, while PD is an immunoinflammatory disease of bacterial origin [9]. However, it is noteworthy that many epidemiological studies seem to dilute the subtle differences expressed by some parameters, though clinically important. Indeed, analyses of inflammatory mediators and other molecular markers are examples where the differences found in a trial with few participants could disappear in a large and diverse sample. In this sense, this review is a critical appraisal of studies that address potential associations of periodontitis with RA and with an overall comprehensive approach.

\section{Methods}

For this review, the US National Library of Medicine National Institutes of Health PubMed was searched by two independent researchers who agreed with the search criteria of studies with patients with both PD and RA and checked by a third researcher separately. The keywords periodontitis and rheumatoid arthritis were used and 367 articles published in English were found. The time period was limited from January 2012 to March 2015, and 162 references were found. Then, a critical reading based on titles and abstracts was made and 136 papers were excluded, such as reviews, assays in vitro and animal studies, articles that were not in English, studies not related to both PD and RA, case study, workshop, or unavailable and incomplete articles. Then, 26 articles were finally included for this review, which related to PD and RA, considering epidemiological aspects, mechanical periodontal treatment, mediators of inflammation, oral microbiota, and antibodies as seen in Figure 2.

\section{Results}

Table 1 shows demographic data, such as gender, age and habits, comorbidities and medications, and the relationship

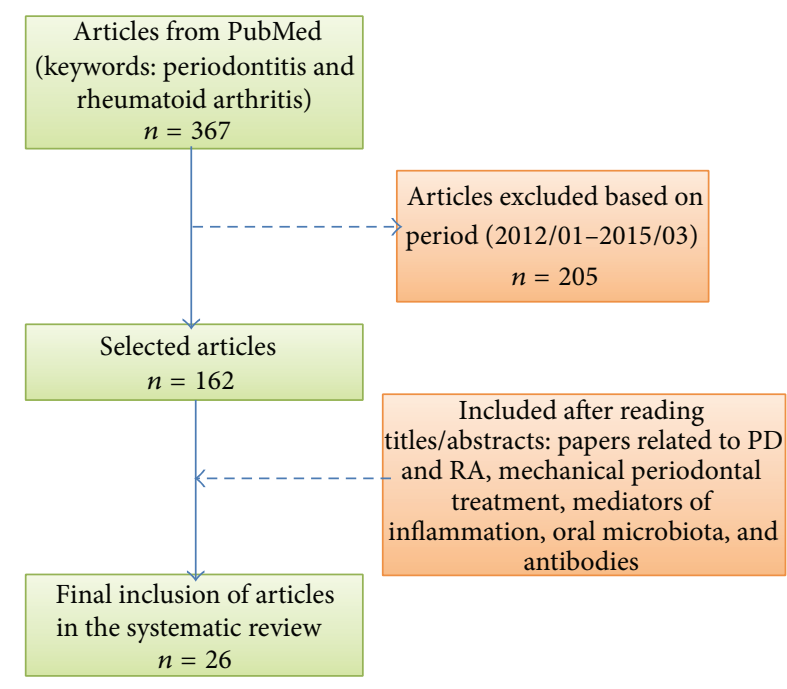

FIGURE 2: Search flow-chart and selection of articles for the review of the literature considering a bit more than the last three years. PD = periodontitis; $\mathrm{RA}=$ rheumatoid arthritis.

between both diseases investigated through clinical and epidemiological associations, presence of oral bacterial DNA in patients with RA, proinflammatory mediators, antibodies against bacteria, and autoantibodies, as well as the effects of mechanical periodontal treatment, related to the 26 selected articles.

In most articles (92.3\%), the analyzed groups were mainly composed of women. Regarding age, most patients were 40 years old, except for the study of Dev et al. (2013) [45] and Ranade and Doiphode (2012) [37], whose patients were above 20 and 30 years old, respectively. Among the 26 articles, 57.7\% $[34-36,38,39,42,50-57,59]$ used samples with smoker patients, while $30.8 \%$ established smoking as criteria for excluding [37, 41, 43, 45-49]. 11.5\% did not mention smoking status of patients $[40,44,58]$. Comorbidities such as diabetes, Sjögren's syndrome, hypertension, cardiovascular disease, hyperlipidemia, renal disease, and osteoporosis/osteopenia have only been reported in studies of Mikuls et al. (2012) [35], Khantisopon et al. (2014) [54], and Gonzales et al. (2015) [59]. Regarding the medication used by patients, 50\% [35-37, 40, $41,44,45,49,50,52,53,55,58]$ of the articles did not specify the pharmacological treatment. In the remainder of the studies, the most frequently reported treatment for rheumatoid arthritis included disease-modifying antirheumatic drugs (methotrexate, sulfasalazine, and leflunomide) $[38,39,42$, $43,46,51,54,56,57,59]$, biologic therapy (anti-TNF- $\alpha$ ) $[34,38,39,42,59]$, corticosteroids (prednisolone) [38, 42, $43,46,51,54,56,59]$, and/or nonsteroidal anti-inflammatory drugs [ $43,46-48,51,54,57]$.

Among the selected trials, eight studies broached the epidemiological and clinical relationship of patients with PD and RA [38,41, 44, 45, 49, 54, 56, 59], indicating a higher prevalence of $\mathrm{PD}$ in patients with RA, which have worse periodontal parameters. The effect of mechanical removal of foci of infection in the oral cavity on the severity of RA and periodontal clinical parameters were shown by four 


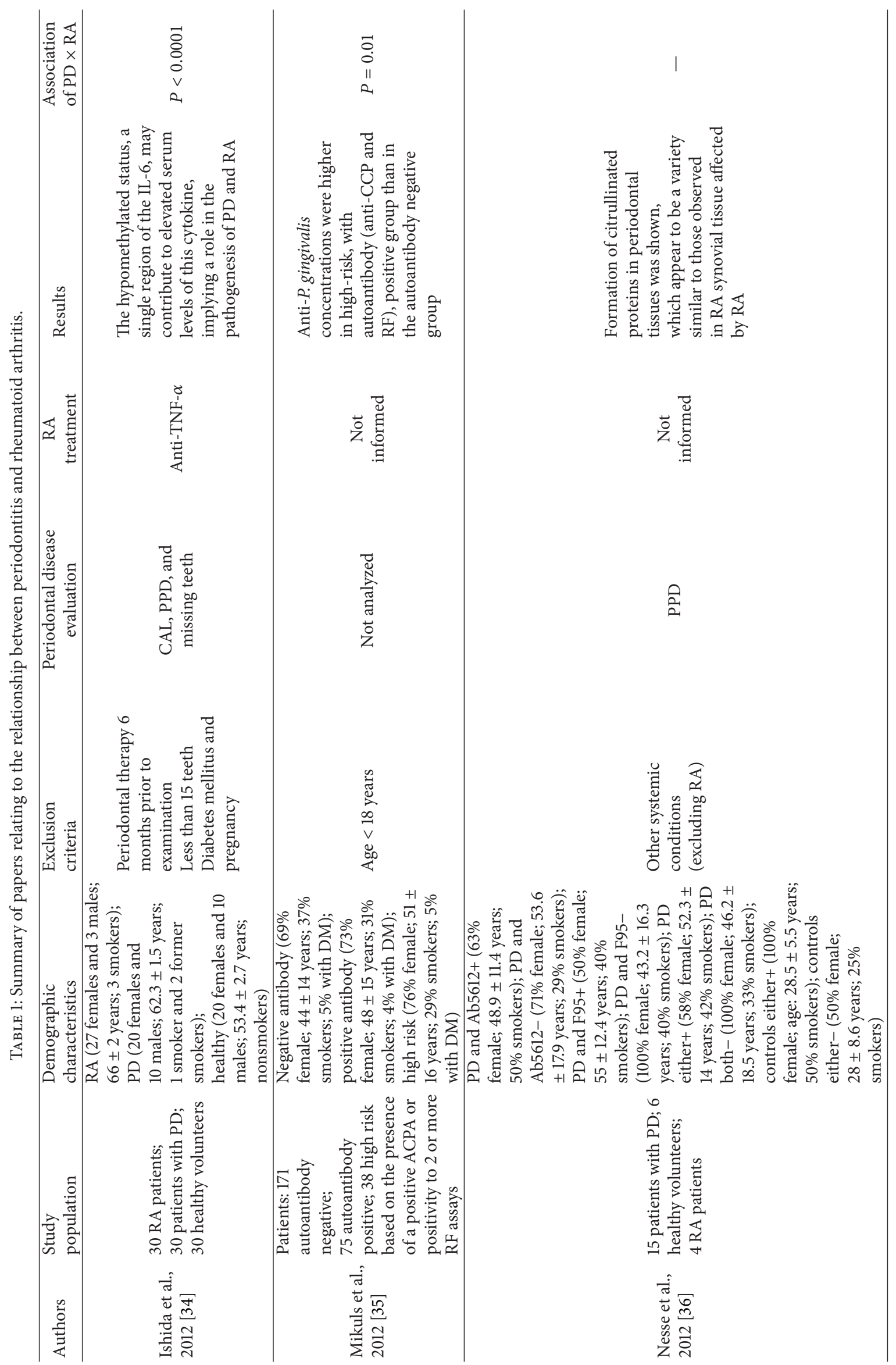




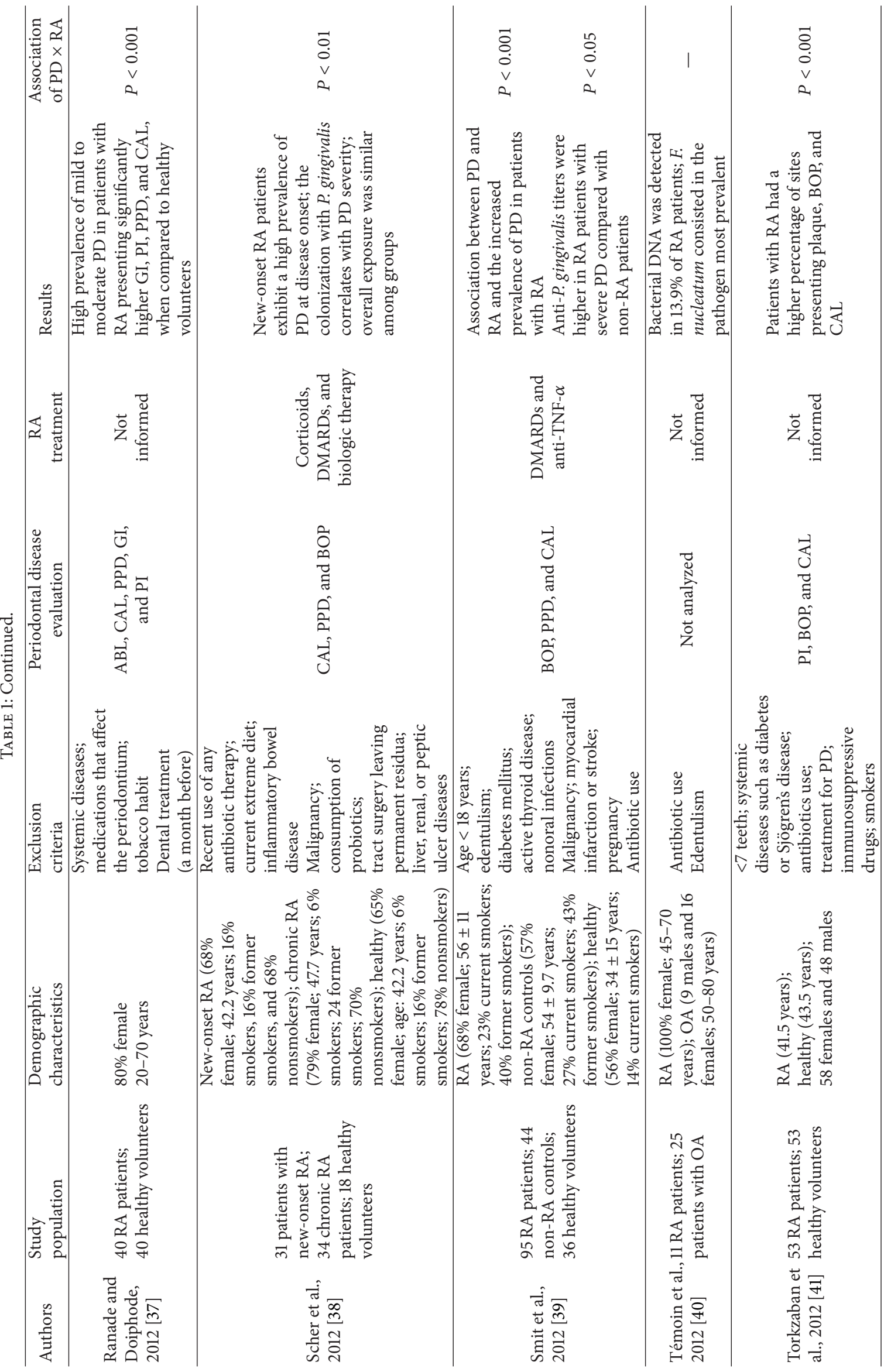




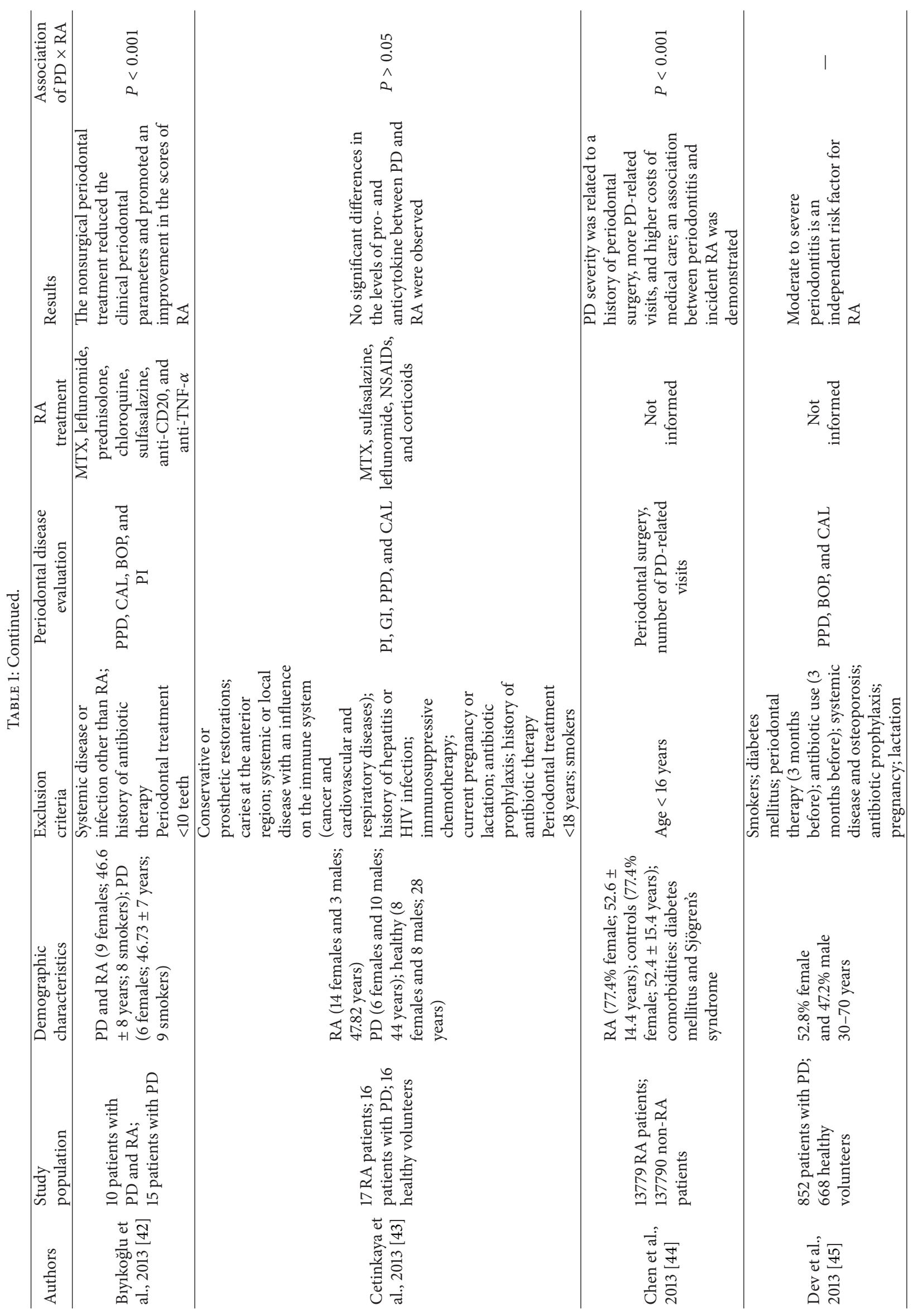




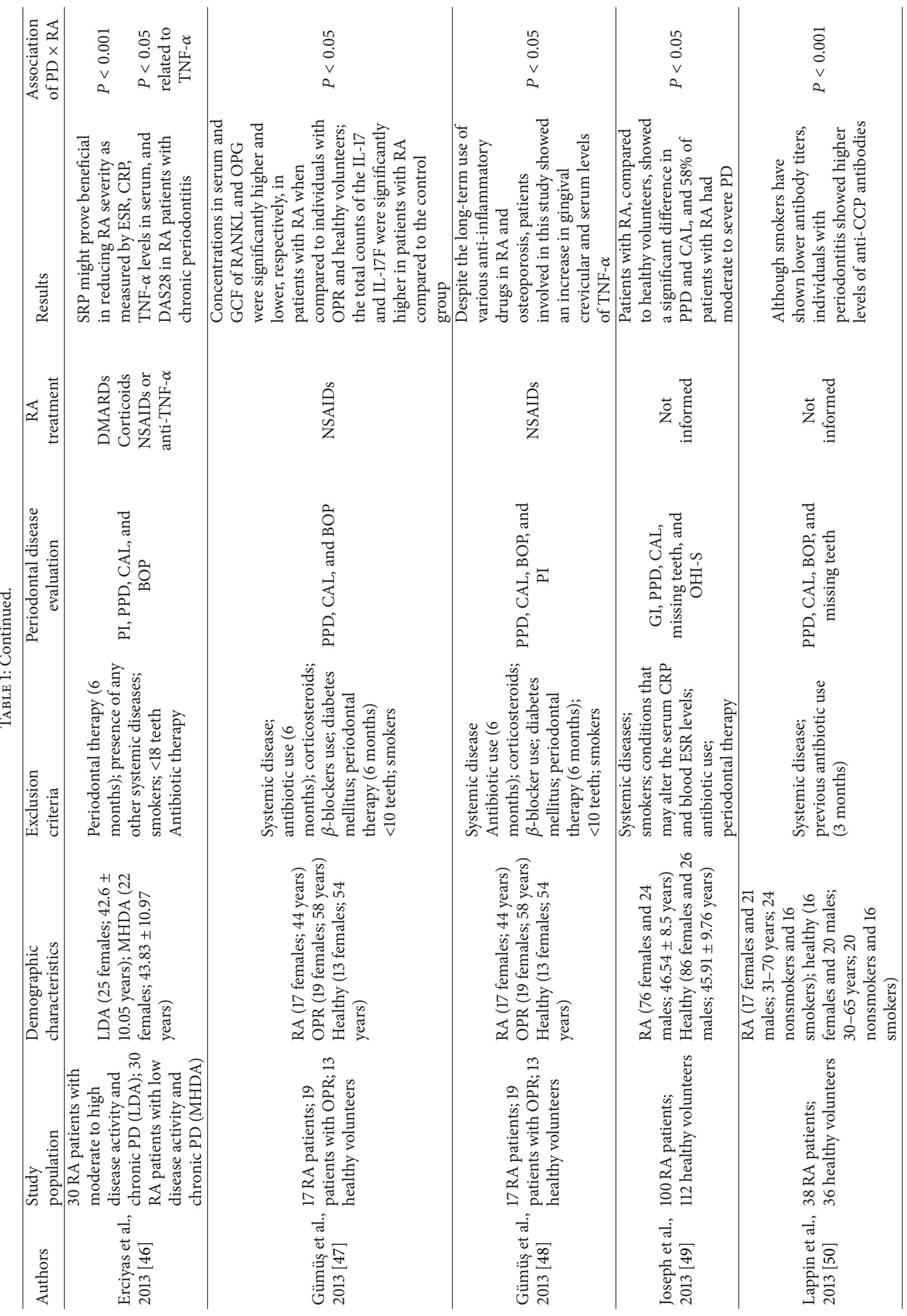




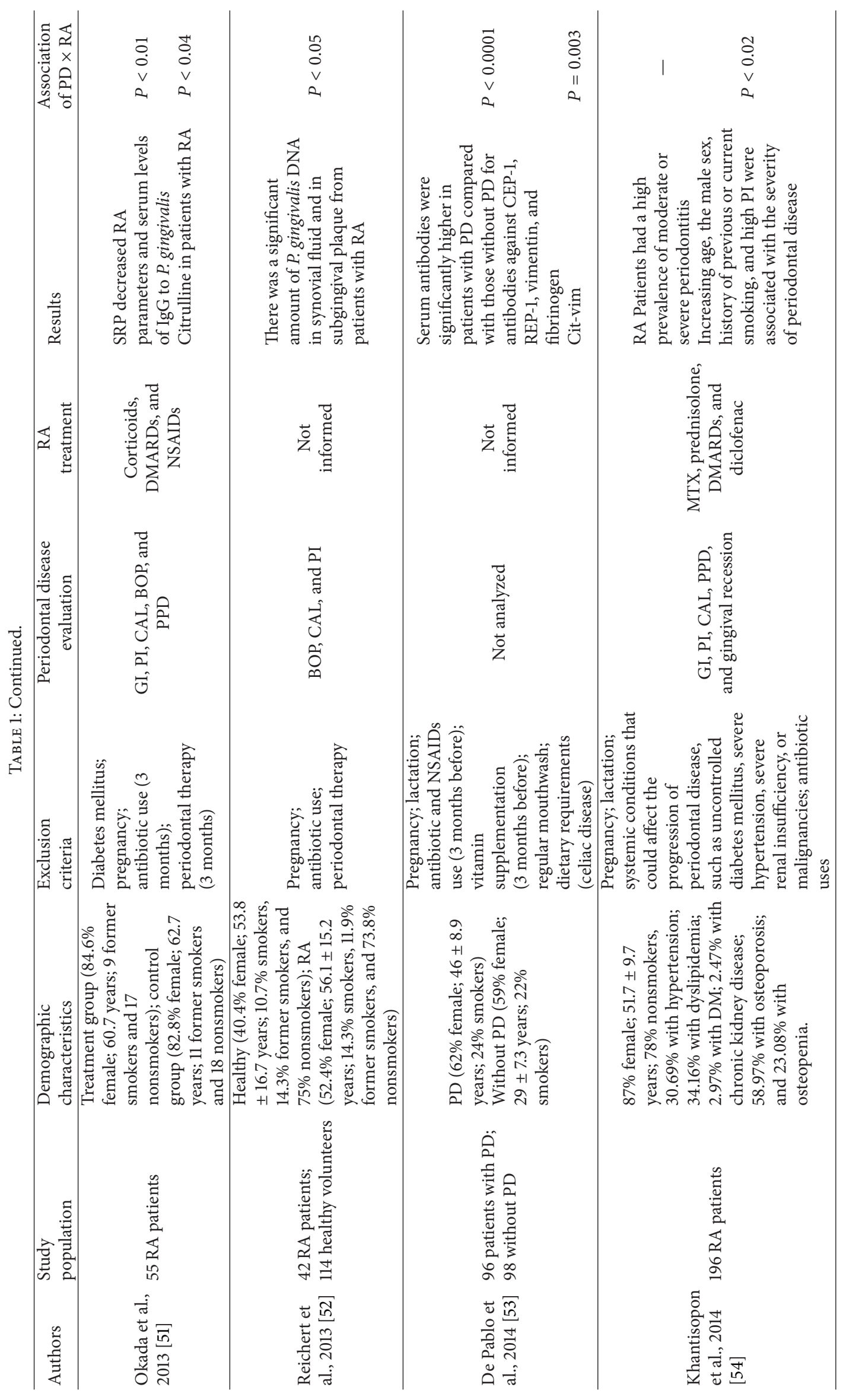




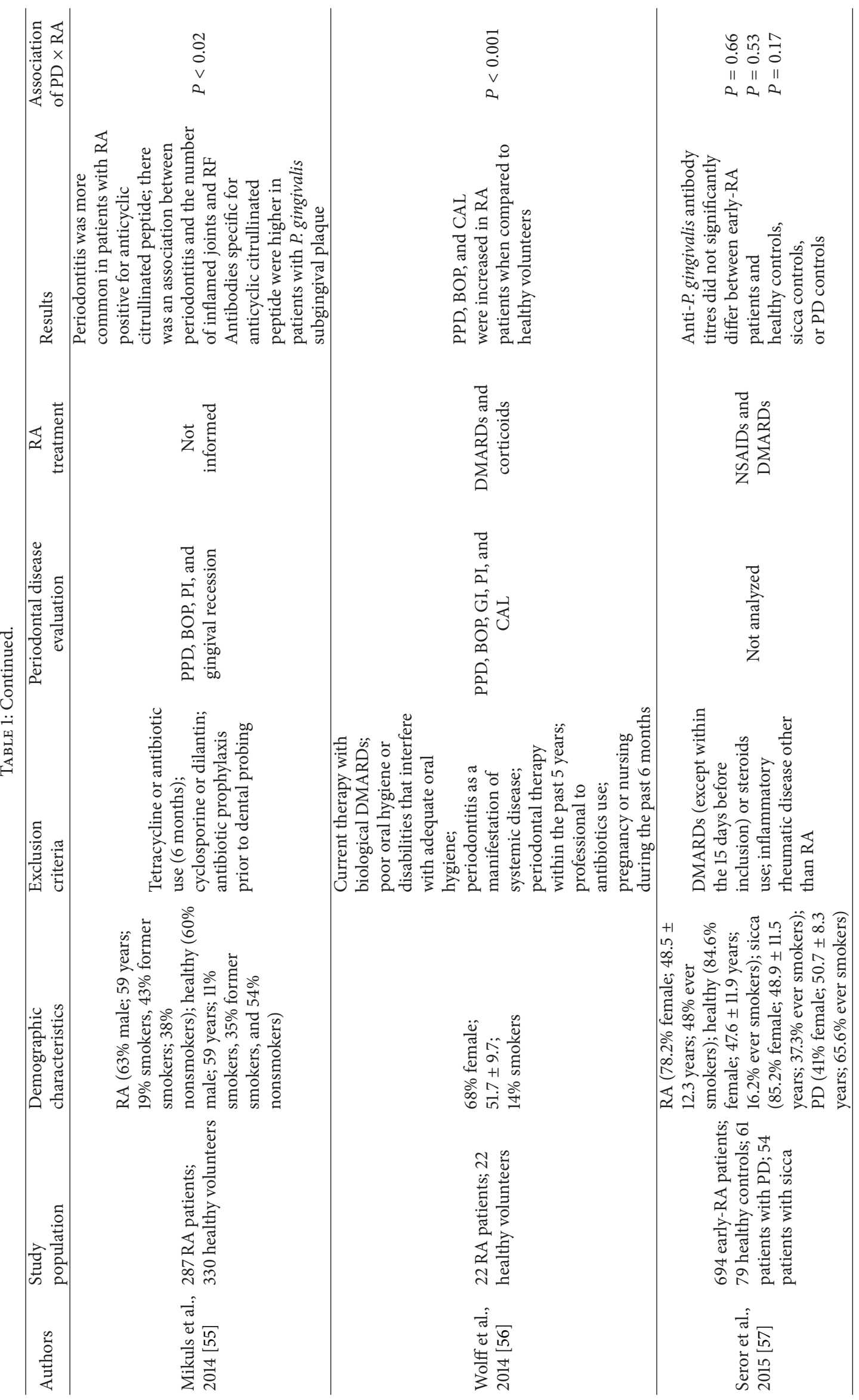




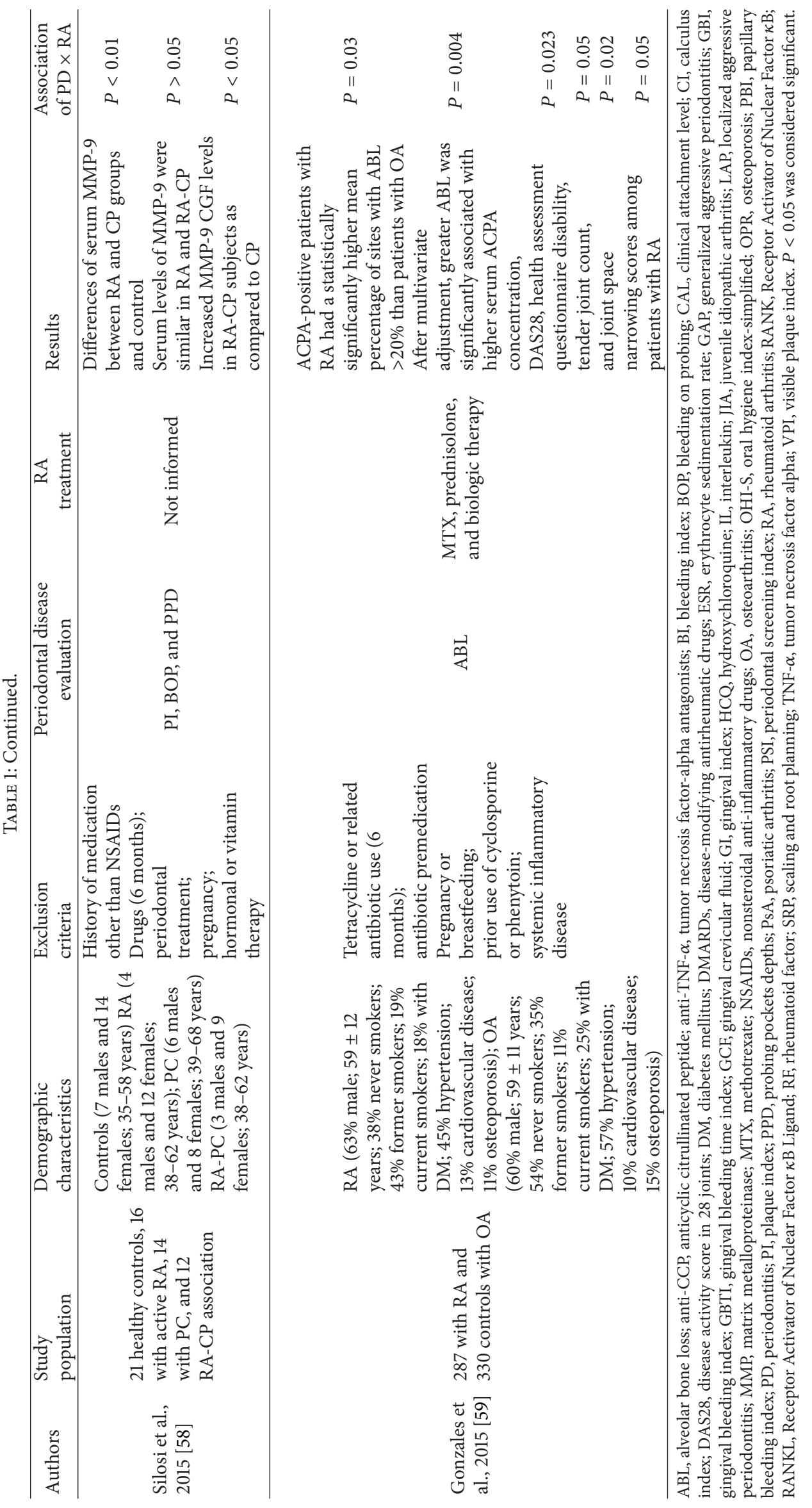


studies [37, 42, 46, 51], which demonstrated the beneficial effects of the mechanical treatment in the improvement of clinical parameters of RA. Two studies were related to the oral bacteria influence of the pathogenesis of RA $[40,52]$. Seven trials highlighted the presence of citrullinated proteins and their antibodies, antibodies to $P$. gingivalis in patients with RA and periodontitis, and also the association between anti- $P$. gingivalis and periodontal parameters, and the titers of rheumatoid factor and antibodies anticyclic citrullinated peptide, which were also related to the severity of $\mathrm{PD}$ [35, $36,39,50,53,55,57]$. Regarding the inflammation in both diseases, five trials considered the mediators of inflammation to the PD and RA $[34,43,47,48,58]$, such as MMP-9, TNF$\alpha$, IL-17, RANKL, and OPG. Considering the relationship between rheumatoid arthritis and periodontitis, only two articles showed no statistical significant association, while 24 studies have established this association, either by descriptive (3 studies) or statistical analysis (21 studies).

\section{Discussion}

In this review, demographic data and other aspects that can modify one or both diseases were presented, as well as the relationship between both diseases investigated through clinical and epidemiological associations, effects of mechanical periodontal treatment, presence of oral bacterial DNA in patients with RA, proinflammatory mediators, antibodies against bacteria, and autoantibodies.

The articles showed higher prevalence of female patients. This aspect was interesting, as a possible relationship between female sex hormones and susceptibility of rheumatoid arthritis had been reported in the literature, so that low levels of those hormones at menopause promote the risk of developing the disease early [60]. However, a protective role of oral contraceptives on the risk for rheumatoid arthritis in women is still controversial [61-63]. On the other hand, there is strong evidence that estrogen deficiency influences the severity of periodontitis, since worse periodontal parameters were observed as bleeding on probing, gingival recession, and clinical attachment loss in postmenopausal women with osteoporosis [64].

The smoking status was also recorded in the selected studies. Cigarette smoking is considered an important risk factor for the development of rheumatoid arthritis, since it was demonstrated that lifelong cigarette smoking was positively associated with the risk of RA even among smokers with a low lifelong exposure [65]. Moreover, it has been related that smoking interacts with HLA-DR SE genes and increases the risk of anti-CCP antibodies in patients with rheumatoid arthritis [66]. Regarding the periodontium, it was shown that smokers presented greater probing depths, when compared to the probing depths of patients who never smoked [67].

The literature shows that $\mathrm{PD}$ does not usually require pharmacological treatment, except for mechanical periodontal treatment as routine. In this review, this fact was also observed, while half of the studies had shown that rheumatoid arthritis involved some pharmacological approach. The use of disease-modifying antirheumatic drugs (DMARDs) aims to reverse the symptoms of the disease, reduce the progression of joint damage, and consequently improve the quality of life of patients [68]. The conventional synthetic DMARDs include methotrexate, sulfasalazine, and leflunomide; the available tumor necrosis factor inhibitors (adalimumab, etanercept, and infliximab), the T cell costimulation inhibitor (abatacept), the anti-B cell agent (rituximab), and the interleukin- 6 receptor blocking monoclonal antibody are included in biological DMARDs [69]. These medications may be associated with glucocorticoids (GC) or nonsteroidal antiinflammatory drugs (NSAIDs). The long-term, low-dose glucocorticoid and NSAIDs therapy were shown to reduce joint symptoms, pain, and other systemic manifestations [70, 71]. Although these benefits are present, the long-time treatment with GC and methotrexate decreased immune response and promoted oral changes, such as candidiasis, periodontitis, and oral ulceration besides impaired saliva secretion [72]. Indeed the literature demonstrated that patients on corticosteroids exhibited higher levels of candidiasis, clinical attachment loss, and probing pocket depth [73]. These aspects, at least in part, may contribute to the worse periodontal status of RA patients when compared to healthy patients. Moreover, the use of medications referred to in half of the articles could compromise the evaluation of this review. However, it is noteworthy that the other half of the articles did not use any medication [35-37, 40, 41, 44, 45, 49, 50, 52, 53, 55, 58].

Analysing the articles, it was observed that most patients with RA showed a significant increase in the incidence of PD as compared to healthy individuals, while only few articles concluded the opposite, probably due to the lack of standardization of parameters in evaluating the different types of periodontitis. Although epidemiological studies outlined by Dev et al. (2013) [45] have not observed a significant RA incidence in subjects with periodontitis where these authors suggested that periodontitis is an independent factor for RA, several other studies have shown that patients with RA were more susceptible to the development of periodontitis [38, 44], since these patients had worse periodontal parameters, such as clinical attachment level $[37,56]$, alveolar bone loss $[56,59]$, probing depth $[37,49]$, plaque index, and bleeding on probing $[37,41,54]$. Indeed, the mechanical periodontal treatment as scaling and root planning in the control of periodontal infection interfered not only with the severity of RA but also with the periodontal clinical parameters [74]. This result can be explained by a reduction in the foci of oral bacteria, and therefore the low levels of inflammation demonstrated a decrease of DAS28 (disease activity score in 28 joints) and serum levels of IL- $1 \beta, \mathrm{TNF}-\alpha, \mathrm{C}$-reactive protein, and erythrocyte rate sedimentation $[37,42,46,51]$. In this sense, studies have defended the hypothesis that oral infections play an important role in the pathogenesis of RA, promoting the citrullination of proteins, which can be based on the detection of bacterial DNA using the techniques of DNA isolation (PCR and DNA-DNA hybridization) and high titers of antibodies against bacteria in synovial fluid and serum samples from patients with RA $[40,51,52]$. Most of the studies have shown the presence of oral bacteria in patients with RA, highlighting P. gingivalis and F. nucleatum [40, 52]. Markedly, 
P. gingivalis is the most elucidated in the development of RA, and studies using animal models have demonstrated the potential of this proinflammatory bacterium promoting the development of experimental arthritis and increased serum levels of C-reactive protein, TNF- $\alpha$, IL-1 $\beta$, IL-17, MMP-13, and RANKL [75]. Furthermore, RA is an autoimmune disease characterized by autoantibodies specific for citrullinated peptide antigen (anticyclic citrullinated peptide), which are synthetized by peptidylarginine deiminase and characterized as the most specific markers for the diagnosis of the disease $[76,77]$. Considering that the $P$. gingivalis is regarded as being capable of expressing this enzyme (PAD), it is suggested that infection with this microorganism could influence the pathogenesis of RA $[78,79]$. These citrullinated proteins were also found in periodontal tissues, indicating a link between these peptides generated in the oral cavity and those observed in articular tissues [36, 80].

Additionally, the presence of antibodies to $P$. gingivalis was investigated. Although Seror et al. (2015) [57] have not detected this, antibody titres significantly differ between early rheumatoid arthritis and healthy controls. Other studies observed the antibodies to $P$. gingivalis in patients with RA and severe periodontitis [39] and were associated with probing depth and clinical attachment level and the titers of rheumatoid factor and anticyclic citrullinated peptide autoantibodies $[35,50]$, which may be found in patients with RA and related to the severity of periodontitis [55]. In summary, the studies suggested that $P$. gingivalis might play a role in the pathogenesis of RA. The response in periodontitis was related to uncitrullinated peptide, suggesting that these peptides break tolerance and can be involved in pathogenesis of RA [53] (Figure 1(c)).

Inflammatory conditions and mechanisms for bone destruction in PD and RA have many similarities. Most of the studies have found high levels of proinflammatory cytokines and other mediators of inflammation, such as MMP-9 [58], TNF- $\alpha$ [48], IL-17, RANKL, and OPG [47]. Moreover, it was demonstrated that the hypomethylated status, a single region of the IL-6, may contribute to elevated serum levels of this cytokine, implying a role in the pathogenesis of these diseases [34], while the anti-inflammatory cytokines in the GCF, such as IL-4 and IL-10, showed no consensus among studies regarding the differences observed among individuals with PD and RA [43]. In addition, hypotheses have been proposed to explain the relationship between periodontitis and systemic diseases, such as rheumatoid arthritis. In the literature, studies have suggested that chronic periodontitis generates local constant high levels of microparticles, which have been considered inflammatory biomarkers or mediators responsible for distant cell signalling and regulation [81]. Moreover, it has been reported that these microparticles play an important role in thrombosis and angiogenesis and mediate cellular communication by transferring mRNAs and microRNAs from the cell of origin to target cells [82]. Thus, the microparticle participation and its spread into the bloodstream could constitute the explanation to the increased risk for systemic disease in patients with periodontitis [83].
Despite these evidences showing a link between rheumatoid arthritis and periodontitis, the exact mechanisms involving this association have not been fully elucidated. Thus, welldesigned longitudinal multicentre clinical trials and further studies with sufficient sample sizes are required to determine the biochemical processes and clinical relationships between these chronic inflammatory conditions. Moreover, these studies should consider other potential confound factors such as the drugs administered for the treatment for each disease or differences in oral hygiene or smoking habits in these patients.

\section{Conclusion}

The majority of the articles have confirmed that there is a correlation between PD and RA, since both disorders have characteristics in common and result from an imbalance in the immunoinflammatory response. Although it is necessary to highlight the importance of the mechanical treatment for periodontitis and pharmacological treatments mainly for RA patients, more research is needed to assess whether the coexistence of both diseases can affect the clinical signs of periodontitis and systemic markers of rheumatoid arthritis and strengthen the capacity of oral bacteria to stimulate an autoimmune response, thus establishing that cell constituents or mediators could share common pathophysiological pathways for both diseases and therefore define the best therapy.

\section{Conflict of Interests}

The authors declare that there is no conflict of interests regarding the publication of this paper.

\section{References}

[1] T. Yucel-Lindberg and T. Båge, "Inflammatory mediators in the pathogenesis of periodontitis," Expert Reviews in Molecular Medicine, vol. 15, article e7, pp. 1-13, 2013.

[2] G. N. Belibasakis, D. Reddi, and N. Bostanci, "Porphyromonas gingivalis induces RANKL in T-cells," Inflammation, vol. 34, no. 2, pp. 133-138, 2011.

[3] A. Stabholz, W. A. Soskolne, and L. Shapira, "Genetic and environmental risk factors for chronic periodontitis and aggressive periodontitis," Periodontology 2000, vol. 53, no. 1, pp. 138-153, 2010.

[4] R. J. Genco and W. S. Borgnakke, "Risk factors for periodontal disease," Periodontology 2000, vol. 62, no. 1, pp. 59-94, 2013.

[5] B. G. Loos, R. P. John, and M. L. Laine, "Identification of genetic risk factors for periodontitis and possible mechanisms of action," Journal of Clinical Periodontology, vol. 32, supplement 6, pp. 159-179, 2005.

[6] Z. Amingohar, J. J. Jorgensen, A. K. Kristoffersen, K. Schenck, and Z. Dembic, "Polymorphisms in the interleukin-10 gene and chronic periodontitis in patients with atherosclerotic and aortic aneurysmal vascular diseases," Journal of Oral Microbiology, vol. 7, Article ID 26051, 2015.

[7] F. G. Teixeira, S. A. Mendonça, K. M. Oliveira et al., "Interleukin-6 c.-174G >C polymorphism and periodontitis in a Brazilian population," Molecular Biology International, vol. 2014, Article ID 490308, 8 pages, 2014. 
[8] G. Nussbaum and L. Shapira, "How has neutrophil research improved our understanding of periodontal pathogenesis?" Journal of Clinical Periodontology, vol. 38, supplement 11, pp. 49-59, 2011.

[9] D. F. Kinane, P. M. Preshaw, and B. G. Loos, "Host-response: understanding the cellular and molecular mechanisms of hostmicrobial interactions-consensus of the Seventh European Workshop on Periodontology," Journal of Clinical Periodontology, vol. 38, supplement 1, pp. 44-48, 2011.

[10] V. Lima, M. M. Bezerra, R. F. C. Leitão, G. A. C. Brito, F. A. C. Rocha, and R. A. Ribeiro, "Principais mediadores inflamatórios envolvidos na fisiopatologia da periodontite-papel dos moduladores farmacológicos," R Periodontia, vol. 18, no. 3, pp. 7-19, 2008.

[11] G. Sapna, S. Gokul, and K. Bagri-Manjrekar, "Matrix metalloproteinases and periodontal diseases," Oral Diseases, vol. 20, no. 6, pp. 538-550, 2014.

[12] M. Faizuddin, S. H. Bharathi, and N. V. Rohini, "Estimation of interleukin-lbeta levels in the gingival crevicular fluid in health and in inflammatory periodontal disease," Journal of Periodontal Research, vol. 38, no. 2, pp. 111-114, 2003.

[13] T. Nakashima, Y. Kobayashi, S. Yamasaki et al., "Protein expression and functional difference of membrane-bound and soluble receptor activator of NF-kappaB ligand: modulation of the expression by osteotropic factors and cytokines," Biochemical and Biophysical Research Communications, vol. 275, no. 3, pp. 768-775, 2000.

[14] M. Hernández, N. Dutzan, J. García-Sesnich et al., "Hostpathogen interactions in progressive chronic periodontitis," Journal of Dental Research, vol. 90, no. 10, pp. 1164-1170, 2011.

[15] J. Bhuvaneswarril, B. Gita, and S. C. Chandrasekaran, "Detection of RANKL positive cells in gingival tissue in healthy and chronic periodontal disease patients-a comparative study," Journal of Clinical and Diagnostic Research, vol. 8, no. 11, pp. 3134, 2014.

[16] P. S. Kumar, "Oral microbiota and systemic disease," Anaerobe, vol. 24, pp. 90-93, 2013

[17] B. T. Garib and S. S. Qaradaxi, "Temporomandibular joint problems and periodontal condition in rheumatoid arthritis patients in relation to their rheumatologic status," Journal of Oral and Maxillofacial Surgery, vol. 69, no. 12, pp. 2971-2978, 2011.

[18] E. Neumann, S. R. Barnum, I. H. Tarner et al., "Local production of complement proteins in rheumatoid arthritis synovium," Arthritis \& Rheumatism, vol. 46, no. 4, pp. 934-945, 2002.

[19] G. A. Liubchenko, H. C. Appleberry, C. C. Striebich et al., "Rheumatoid arthritis is associated with signaling alterations in naturally occurring autoreactive B-lymphocytes," Journal of Autoimmunity, vol. 40, no. 1, pp. 111-121, 2013.

[20] I. B. McInnes and G. Schett, "The pathogenesis of rheumatoid arthritis," The New England Journal of Medicine, vol. 365, no. 23, pp. 2205-2219, 2011.

[21] P. S. Burrage, K. S. Mix, and C. E. Brinckerhoff, "Matrix metalloproteinases: role in arthritis," Frontiers in Bioscience, vol. 11, no. 1, pp. 529-543, 2006.

[22] H. Li and A. Wan, "Apoptosis of rheumatoid arthritis fibroblastlike synoviocytes: possible roles of nitric oxide and the thioredoxin 1," Mediators of Inflammation, vol. 2013, Article ID 953462, 8 pages, 2013.

[23] C. M. Weyand, "New insights into the pathogenesis of rheumatoid arthritis," Rheumatology, vol. 39, supplement 1, pp. 3-8, 2000 .
[24] S. Xu, Y. Wang, J. Lu, and J. Xu, "Osteoprotegerin and RANKL in the pathogenesis of rheumatoid arthritis-induced osteoporosis," Rheumatology International, vol. 32, no. 11, pp. 3397-3403, 2012.

[25] J. K. De Vries-Bouwstra, Y. P. M. Goekoop-Ruiterman, K. N. Verpoort et al., "Progression of joint damage in early rheumatoid arthritis: association with HLA-DRB1, rheumatoid factor, and anti-citrullinated protein antibodies in relation to different treatment strategies," Arthritis and Rheumatism, vol. 58, no. 5, pp. 1293-1298, 2008.

[26] H. Källberg, L. Padyukov, R. M. Plenge et al., "Gene-gene and gene-environment interactions involving HLA-DRB1, PTPN22, and smoking in two subsets of rheumatoid arthritis," The American Journal of Human Genetics, vol. 80, no. 5, pp. 867-875, 2007.

[27] F. A. S. Kurreeman, L. Padyukov, R. B. Marques et al., "A candidate gene approach identifies the TRAF1/C5 region as a risk factor for rheumatoid arthritis," PLoS Medicine, vol. 4, no. 9, pp. 1515-1524, 2007.

[28] B. Vaidya, S. H. S. Pearce, S. Charlton et al., "An association between the CTLA4 exon 1 polymorphism and early rheumatoid arthritis with autoimmune endocrinopathies," Rheumatology, vol. 41, no. 2, pp. 180-183, 2002.

[29] R. Raijmakers, J. J. B. C. van Beers, M. El-Azzouny et al., "Elevated levels of fibrinogen-derived endogenous citrullinated peptides in synovial fluid of rheumatoid arthritis patients," Arthritis Research and Therapy, vol. 14, no. 3, article R114, 2012.

[30] L. Klareskog, P. Stolt, K. Lundberg et al., "A new model for an etiology of rheumatoid arthritis: smoking may trigger HLA-DR (shared epitope)-restricted immune reactions to autoantigens modified by citrullination," Arthritis and Rheumatism, vol. 54, no. 1, pp. 38-46, 2006.

[31] M. J. H. de Hair, R. B. M. Landewé, M. G. H. van de Sande et al., "Smoking and overweight determine the likelihood of developing rheumatoid arthritis," Annals of the Rheumatic Diseases, vol. 72, no. 10, pp. 1654-1658, 2013.

[32] M. Pedersen, S. Jacobsen, M. Klarlund et al., "Environmental risk factors differ between rheumatoid arthritis with and without auto-antibodies against cyclic citrullinated peptides," Arthritis Research and Therapy, vol. 8, no. 4, pp. 1-15, 2006.

[33] K. Moen, J. G. Brun, M. Valen et al., "Synovial inflammation in active rheumatoid arthritis and psoriatic arthritis facilitates trapping of a variety of oral bacterial DNAs," Clinical and Experimental Rheumatology, vol. 24, no. 6, pp. 656-663, 2006.

[34] K. Ishida, T. Kobayashi, S. Ito et al., "Interleukin-6 gene promoter methylation in rheumatoid arthritis and chronic periodontitis," Journal of Periodontology, vol. 83, no. 7, pp. 917-925, 2012.

[35] T. R. Mikuls, G. M. Thiele, K. D. Deane et al., "Porphyromonas gingivalis and disease-related autoantibodies in individuals at increased risk of rheumatoid arthritis," Arthritis and Rheumatism, vol. 64, no. 11, pp. 3522-3530, 2012.

[36] W. Nesse, J. Westra, J. E. van der Wal et al., “The periodontium of periodontitis patients contains citrullinated proteins which may play a role in ACPA (anti-citrullinated protein antibody) formation," Journal of Clinical Periodontology, vol. 39, no. 7, pp. 599-607, 2012.

[37] S. B. Ranade and S. Doiphode, "Is there a relationship between periodontitis and rheumatoid arthritis," Journal of Indian Society of Periodontology, vol. 16, no. 1, pp. 22-27, 2012.

[38] J. U. Scher, C. Ubeda, M. Equinda et al., "Periodontal disease and the oral microbiota in new-onset rheumatoid arthritis," Arthritis and Rheumatism, vol. 64, no. 10, pp. 3083-3094, 2012. 
[39] M. D. Smit, J. Westra, A. Vissink, B. Doornbos-van der Meer, E. Brouwer, and A. J. van Winkelhoff, "Periodontitis in established rheumatoid arthritis patients: a cross-sectional clinical, microbiological and serological study," Arthritis Research and Therapy, vol. 14, no. 5, article R222, 2012.

[40] S. Témoin, A. Chakaki, A. Askari et al., "Identification of oral bacterial DNA in synovial fluid of patients with arthritis with native and failed prosthetic joints," Journal of Clinical Rheumatology, vol. 18, no. 3, pp. 117-121, 2012.

[41] P. Torkzaban, T. Hjiabadi, Z. Basiri, and J. Poorolajal, "Effect of rheumatoid arthritis on periodontitis: a historical cohort study," Journal of Periodontal and Implant Science, vol. 42, no. 3, pp. 6772, 2012.

[42] B. Bıyıkoğlu, N. Buduneli, K. Aksu et al., "Periodontal therapy in chronic periodontitis lowers gingival crevicular fluid interleukin-1beta and DAS28 in rheumatoid arthritis patients," Rheumatology International, vol. 33, no. 10, pp. 2607-2616, 2013.

[43] B. Cetinkaya, E. Guzeldemir, E. Ogus, and S. Bulut, "Proinflammatory and anti-inflammatory cytokines in gingival crevicular fluid and serum of patients with rheumatoid arthritis and patients with chronic periodontitis," Journal of Periodontology, vol. 84, no. 1, pp. 84-93, 2013.

[44] H.-H. Chen, N. Huang, Y.-M. Chen et al., "Association between a history of periodontitis and the risk of rheumatoid arthritis: a nationwide, population-based, case-control study," Annals of the Rheumatic Diseases, vol. 72, no. 7, pp. 1206-1211, 2013.

[45] Y. P. Dev, N. Khuller, P. Basavaraj, and G. Suresh, "Rheumatoid arthritis among periodontitis patients in baddi industrial estate of himachal pradesh, India: a cross sectional study," Journal of Clinical and Diagnostic Research, vol. 7, no. 10, pp. 2334-2337, 2013.

[46] K. Erciyas, U. Sezer, K. Üstün et al., "Effects of periodontal therapy on disease activity and systemic inflammation in rheumatoid arthritis patients," Oral Diseases, vol. 19, no. 4, pp. 394400, 2013.

[47] P. Gümüş, E. Buduneli, B. Başak et al., "Gingival crevicular fluid, serum levels of receptor activator of nuclear factor- $\kappa \mathrm{b}$ ligand, osteoprotegerin, and interleukin-17 in patients with rheumatoid arthritis and osteoporosis and with periodontal disease," Journal of Periodontology, vol. 84, no. 11, pp. 1627-1637, 2013.

[48] P. Gümüş, E. Buduneli, B. Bıyıkoğlu et al., "Gingival crevicular fluid and serum levels of APRIL, BAFF and TNF-alpha in rheumatoid arthritis and osteoporosis patients with periodontal disease," Archives of Oral Biology, vol. 58, no. 10, pp. 1302-1308, 2013.

[49] R. Joseph, S. Rajappan, S. G. Nath, and B. J. Paul, "Association between chronic periodontitis and rheumatoid arthritis: a hospital-based case-control study," Rheumatology International, vol. 33, no. 1, pp. 103-109, 2013.

[50] D. F. Lappin, D. Apatzidou, A.-M. Quirke et al., "Influence of periodontal disease, Porphyromonas gingivalis and cigarette smoking on systemic anti-citrullinated peptide antibody titres," Journal of Clinical Periodontology, vol. 40, no. 10, pp. 907-915, 2013.

[51] M. Okada, T. Kobayashi, S. Ito et al., "Periodontal treatment decreases levels of antibodies to porphyromonas gingivalis and citrulline in patients with rheumatoid arthritis and periodontitis," Journal of Periodontology, vol. 84, no. 12, pp. e74-e84, 2013.

[52] S. Reichert, M. Haffner, G. Keyßer et al., "Detection of oral bacterial DNA in synovial fluid," Journal of Clinical Periodontology, vol. 40, no. 6, pp. 591-598, 2013.
[53] P. De Pablo, T. Dietrich, I. L. C. Chapple et al., “The autoantibody repertoire in periodontitis: a role in the induction of autoimmunity to citrullinated proteins in rheumatoid arthritis?" Annals of the Rheumatic Diseases, vol. 73, no. 3, pp. 580586, 2014.

[54] N. Khantisopon, W. Louthrenoo, N. Kasitanon et al., "Periodontal disease in Thai patients with rheumatoid arthritis," International Journal of Rheumatic Diseases, vol. 17, no. 5, pp. 511-518, 2014.

[55] T. R. Mikuls, J. B. Payne, F. Yu et al., "Periodontitis and porphyromonas gingivalis in patients with rheumatoid arthritis," Arthritis and Rheumatology, vol. 66, no. 5, pp. 1090-1100, 2014.

[56] B. Wolff, T. Berger, C. Frese et al., "Oral status in patients with early rheumatoid arthritis: a prospective, case-control study," Rheumatology, vol. 53, no. 3, pp. 526-531, 2014.

[57] R. Seror, S. le Gall-David, M. Bonnaure-Mallet et al., "Association of anti-Porphyromonas gingivalis antibody titers with nonsmoking status in early rheumatoid arthritis: results from the prospective french cohort of patients with early rheumatoid arthritis," Arthritis \& Rheumatology, vol. 67, no. 7, pp. 1729-1737, 2015.

[58] I. Silosi, M. Cojocaru, L. Foia et al., "Significance of circulating and crevicular matrix metalloproteinase-9 in rheumatoid arthritis-chronic periodontitis association," Journal of Immunology Research, vol. 2015, Article ID 218060, 6 pages, 2015.

[59] S. M. Gonzales, J. B. Payne, F. Yu et al., "Alveolar bone loss is associated with circulating anti-citrullinated proteins antibody (ACPA) in patients with rhematoid arthritis," Journal of Periodontology, vol. 86, no. 2, pp. 221-231, 2015.

[60] M. Pikwer, U. Bergström, J.-Å. Nilsson, L. T. Jacobsson, and C. Turesson, "Early menopause is an independent predictor of rheumatoid arthritis," Annals of the Rheumatic Diseases, vol. 71, no. 3, pp. 378-381, 2012.

[61] M. F. Doran, C. S. Crowson, W. M. O'Fallon, and S. E. Gabriel, "The effect of oral contraceptives and estrogen-replacement therapy on the risk of rheumatoid arthritis: a population based study," The Journal of Rheumatology, vol. 31, no. 2, pp. 207-213, 2004.

[62] E. M. Camacho, M. Lunt, T. M. Farragher, S. M. M. Verstappen, D. K. Bunn, and D. P. M. Symmons, "The relationship between oral contraceptive use and functional outcome in women with recent-onset inflammatory polyarthritis: results from the Norfolk Arthritis Register," Arthritis and Rheumatism, vol. 63, no. 8, pp. 2183-2191, 2011.

[63] S. Qi, R. Xin, W. Guo, and Y. Liu, "Meta-analysis of oral contraceptives and rheumatoid arthritis risk in women," Therapeutics and Clinical Risk Management, vol. 10, pp. 915-923, 2014.

[64] E. Pepelassi, K. Nicopoulou-Karayianni, A. D. Archontopoulou et al., "The relationship between osteoporosis and periodontitis in women aged 45-70years," Oral Diseases, vol. 18, no. 4, pp. 353-359, 2012.

[65] D. Di Giuseppe, A. Discacciati, N. Orsini, and A. Wolk, "Cigarette smoking and risk of rheumatoid arthritis: a dose-response meta-analysis," Arthritis Research \& Therapy, vol. 16, no. 2, article R61, 7 pages, 2014.

[66] Y. H. Lee, S.-C. Bae, and G. G. Song, "Gene-environmental interaction between smoking and shared epitope on the development of anti-cyclic citrullinated peptide antibodies in rheumatoid arthritis: a meta-analysis," International Journal of Rheumatic Diseases, vol. 17, no. 5, pp. 528-535, 2014.

[67] M. Razali, R. M. Palmer, P. Coward, and R. F. Wilson, "A retrospective study of periodontal disease severity in smokers and 
non-smokers," British Dental Journal, vol. 198, no. 8, pp. 495498, 2005.

[68] J. S. Smolen, D. Aletaha, M. Koeller, M. H. Weisman, and P. Emery, "New therapies for treatment of rheumatoid arthritis," The Lancet, vol. 370, no. 9602, pp. 1861-1874, 2007.

[69] J. S. Smolen, D. Van Der Heijde, K. P. MacHold, D. Aletaha, and R. Landewé, "Proposal for a new nomenclature of diseasemodifying antirheumatic drugs," Annals of the Rheumatic Diseases, vol. 73, no. 1, pp. 3-5, 2014.

[70] M. Cutolo, C. M. Spies, F. Buttgereit, S. Paolino, and C. Pizzorni, "The supplementary therapeutic DMARD role of low-dose glucocorticoids in rheumatoid arthritis," Arthritis Research \& Therapy, vol. 16, supplement 2, pp. 1-6, 2014.

[71] L. J. Crofford, "Use of NSAIDs in treating patients with arthritis," Arthritis Research and Therapy, vol. 15, no. 3, article S2, 2013.

[72] G. M. J. Deeming, J. Collingwood, and M. N. Pemberton, "Methotrexate and oral ulceration," British Dental Journal, vol. 198, no. 2, pp. 83-85, 2005.

[73] S. S. Beeraka, K. Natarajan, R. Patil, P. K. Manne, V. S. Prathi, and V. S. Kolaparthi, "Clinical and radiological assessment of effects of long-term corticosteroids therapy on oral health," Dental Research Journal, vol. 10, no. 5, pp. 666-673, 2013.

[74] M. K. Al-Katma, N. F. Bissada, J. M. Bordeaux, J. Sue, and A. D. Askari, "Control of periodontal infection reduces the severity of active rheumatoid arthritis," Journal of Clinical Rheumatology, vol. 13, no. 3, pp. 134-137, 2007.

[75] M. D. Cantley, D. R. Haynes, V. Marino, and P. M. Bartold, "Preexisting periodontitis exacerbates experimental arthritis in a mouse model," Journal of Clinical Periodontology, vol. 38, no. 6, pp. 532-541, 2011.

[76] D. Manivelavan and C. K. Vijayasamundeeswari, "Anti-cyclic citrullinated peptide antibody: an early diagnostic and prognostic biomarker of rheumatoid arthritis," Journal of Clinical and Diagnostic Research, vol. 6, no. 8, pp. 1393-1396, 2012.

[77] M. T. Maehlen, I. C. Olsen, B. K. Andreassen et al., "Genetic risk scores and number of autoantibodies in patients with rheumatoid arthritis," Annals of the Rheumatic Diseases, vol. 74, pp. 762-768, 2015.

[78] W. T. McGraw, J. Potempa, D. Farley, and J. Travis, "Purification, characterization, and sequence analysis of a potential virulence factor from Porphyromonas gingivalis, peptidylarginine deiminase," Infection and Immunity, vol. 67, no. 7, pp. 3248-3256, 1999.

[79] N. Wegner, R. Wait, A. Sroka et al., "Peptidylarginine deiminase from Porphyromonas gingivalis citrullinates human fibrinogen and $\alpha$-enolase: implications for autoimmunity in rheumatoid arthritis," Arthritis and Rheumatism, vol. 62, no. 9, pp. 26622672, 2010.

[80] G. P. Harvey, T. R. Fitzsimmons, A. A. S. S. K. Dhamarpatni, C. Marchant, D. R. Haynes, and P. M. Bartold, "Expression of peptidylarginine deiminase- 2 and -4 , citrullinated proteins and anti-citrullinated protein antibodies in human gingiva," Journal of Periodontal Research, vol. 48, no. 2, pp. 252-261, 2013.

[81] M. C. Martinez, S. Tual-Chalot, D. Leonetti, and R. Andriantsitohaina, "Microparticles: targets and tools in cardiovascular disease," Trends in Pharmacological Sciences, vol. 32, no. 11, pp. 659-665, 2011.

[82] T. Burnouf, H. A. Goubran, M.-L. Chou, D. Devos, and M. Radosevic, "Platelet microparticles: detection and assessment of their paradoxical functional roles in disease and regenerative medicine," Blood Reviews, vol. 28, no. 4, pp. 155-166, 2014.
[83] Z. Badran, X. Struillou, C. Verner et al., "Periodontitis as a risk factor for systemic disease: are microparticles the missing link?" Medical Hypotheses, vol. 84, no. 6, pp. 555-556, 2015. 


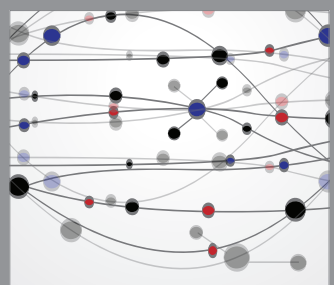

The Scientific World Journal
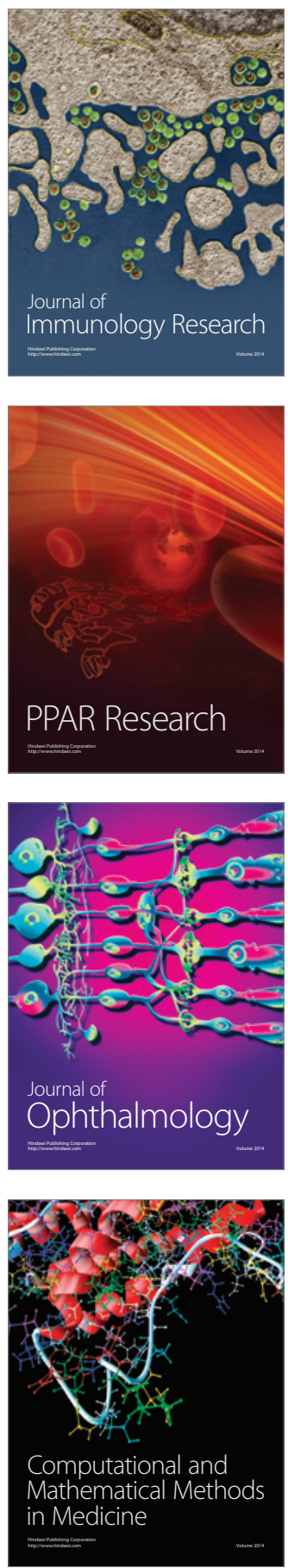

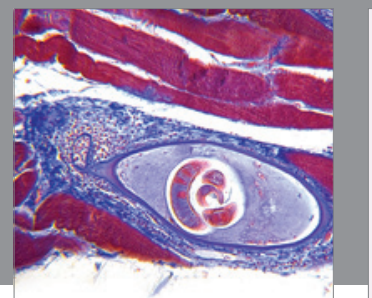

Gastroenterology

Research and Practice
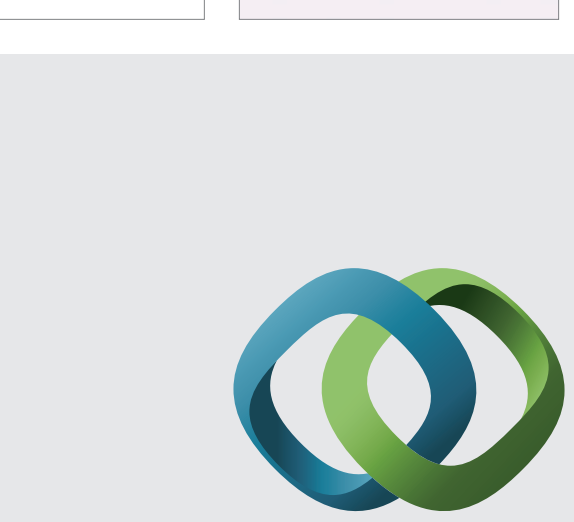

\section{Hindawi}

Submit your manuscripts at

http://www.hindawi.com
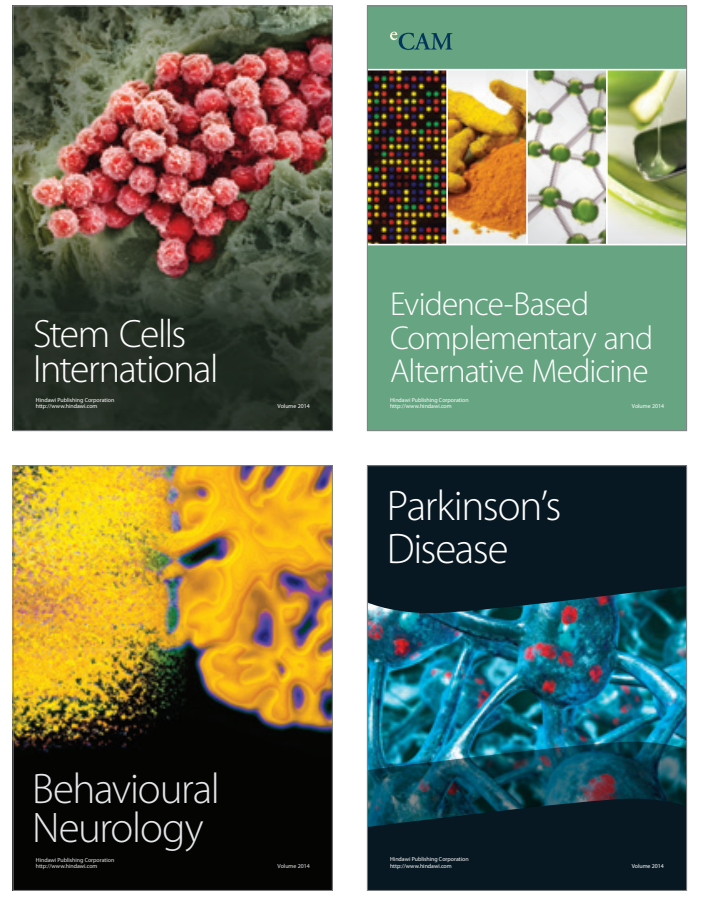
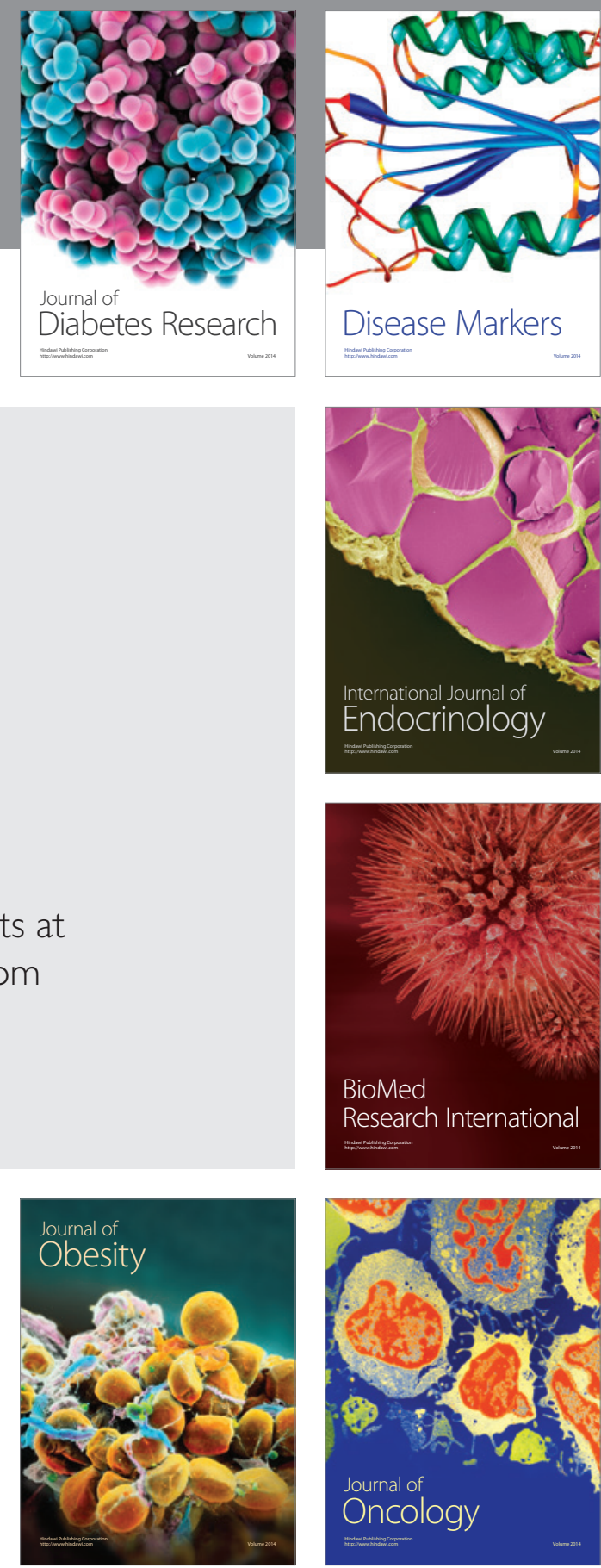

Disease Markers
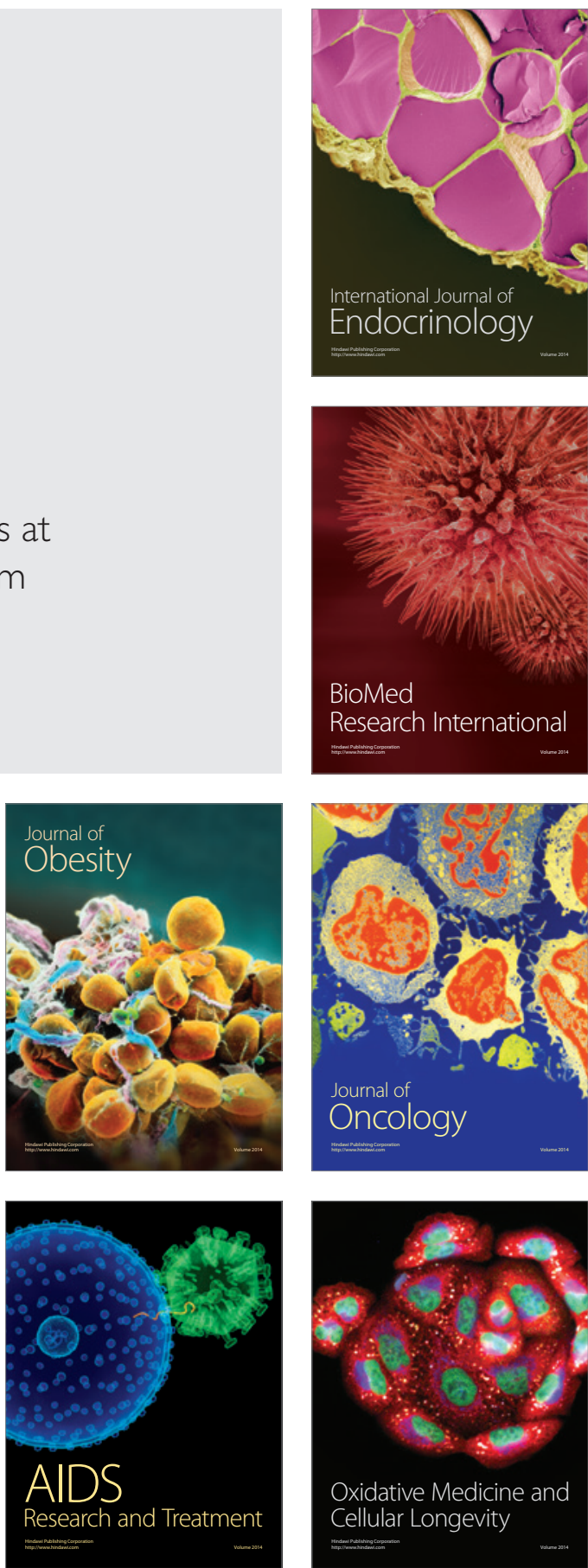